\title{
Frações da matéria orgânica de Latossolo sob influência de doses de lodo de esgoto
}

\author{
Emanuelle Mercês Barros Soares ${ }^{(1)}$, Carlos Alberto Silva(2), Bruno de Oliveira Dias ${ }^{(2)}$, \\ Wagner Bettiol(3) e Maísa Honório Belizário(4)
}

(1)Universidade Federal de Viçosa, Departamento de Solos, CEP 36570-000 Viçosa, MG. E-mail: mercessoares@yahoo.com.br ${ }^{(2)}$ Universidade Federal
de Lavras, Departamento de Ciência do Solo, Caixa Postal 3037, CEP 37200-000 Lavras, MG. E-mail: csilva@ufla.br, b2dias@yahoo.com.br (3)Embrapa
Meio Ambiente, Caixa Postal 69, CEP 13820-000 Jaguariúna, SP. E-mail: bettiol@cnpma.embrapa.br ${ }^{(4)}$ Escola Superior de Agricultura Luiz de
Queiroz, Departamento de Solos e Nutrição de Plantas, Caixa Postal 09, CEP 13418-900 Piracicaba, SP. E-mail: maisaagro@yahoo.com.br

Resumo - O objetivo deste trabalho foi avaliar o efeito da aplicação contínua de doses crescentes de lodo de esgoto sobre os teores de carbono (C) associados à fração leve (C-FL) e à fração pesada (associado à areia - C-areia; associado ao silte - C-silte - e associado à argila - C-argila) de matéria orgânica em amostras de Latossolo. O experimento foi instalado em 1999, em Jaguariúna, SP, e os dados foram obtidos após a sexta aplicação de lodo de esgoto com doses acumuladas em base seca - 0, 30, 60, 120 e $240 \mathrm{Mg} \mathrm{ha}^{-1}$-, após seis cultivos subseqüentes de milho. Os tratamentos foram: testemunha, sem adição de lodo (L0); aplicação de lodo de esgoto para fornecer uma (L1), duas (L2), quatro (L4) e oito (L8) vezes a dose de nitrogênio requerida pelo milho. Como referência, foi amostrada uma área sob mata nativa, adjacente ao local do experimento. $\mathrm{O}$ acréscimo nas doses de lodo de esgoto aplicadas aumenta de modo linear os teores de C orgânico, C-silte e $\mathrm{C}$-areia, e não interfere nos teores de C-argila. À medida que se aumenta a dose de lodo de esgoto até $120 \mathrm{Mg} \mathrm{ha}^{-1}$, há acréscimo no teor de C-FL no solo. Em relação ao C orgânico, os teores de $\mathrm{C}$ associado aos compartimentos avaliados de matéria orgânica do solo têm a seguinte ordem de contribuição: $\mathrm{C}$ - $\mathrm{FL}<\mathrm{C}$-areia $<\mathrm{C}$-silte $<\mathrm{C}$-argila.

Termos para indexação: fração leve, fração pesada, fracionamento físico-densimétrico.

\section{Organic matter fractions of an Oxisol under influence of sewage sludge doses}

\begin{abstract}
The objective of this work was to evaluate the effect of the continued application of increasing doses of sewage sludge on the contents of carbon (C) associated to the light fraction (LF-C) and to the heavy fraction (sand-C, silt-C and clay-C) of soil organic matter, in Oxisol samples. The experiment was installed in 1999, in Jaguariúna, SP, Brazil. The data were obtained after the sixth sewage sludge (SS) application, and six corn cultivation cycles with accumulated doses (dry base) 0, 30, 60, 120 and $240 \mathrm{Mg} \mathrm{ha}^{-1}$, and the treatments were: control, without sewage sludge addition (LO); application of sewage sludge to furnish one (L1), two (L2), four (L4), and eight (L8) times the $\mathrm{N}$ required by corn. As a reference, an adjacent area under forest was also sampled. The increase in the applied sewage sludge doses increases linearly the content of organic $\mathrm{C}$ (org C), silt-C and sand-C. As the sewage sludge dose is increased up to $120 \mathrm{Mg} \mathrm{ha}^{-1}$, there is an increase in the content of LF-C. The content of $\mathrm{C}$ associated to the evaluated compartments of soil organic matter follows this contribution order: FL-C $<$ sand-C $<$ silt-C $<$ clay-C.
\end{abstract}

Index terms: light fraction, heavy fraction, physico-densimetric fractionation.

\section{Introdução}

A matéria orgânica (MO) atua na regulação de diferentes processos do solo, como a ciclagem e a disponibilidade de nutrientes, a solubilização de fertilizantes, a complexação de metais tóxicos, o poder tampão, o fluxo de gases para a atmosfera e a estabilidade de agregados (Stevenson, 1994). No solo são encontradas diferentes substâncias orgânicas, desde materiais livres e com elevada biodisponibilidade, até compostos mais estabilizados quimicamente, em íntima associação com a fase mineral (Christensen, 1992). As frações orgânicas que apresentam elevada taxa de ciclagem e que respondem mais rapidamente às mudanças do uso do solo correspondem a uma pequena fração do C orgânico (Christensen, 1996). Em geral, os indicadores mais responsivos às alterações da qualidade do solo são os associados aos compartimentos mais

Pesq. agropec. bras., Brasília, v.43, n.9, p.1231-1240, set. 2008 
lábeis da $\mathrm{MO}$, como é o caso do compartimento associado à fração leve (FL) (Stevenson, 1994).

A fração leve corresponde à MO livre, que representa de 10 a $30 \%$ do C orgânico (Silva \& Resck, 1997). Os teores de $\mathrm{C}$ associados à fração leve (C-FL) variam com o tipo de solo, clima e práticas de manejo adotadas e a FL é ciclada em menor tempo do que a MO como um todo (Janzen et al, 1992; Silva \& Resck, 1997). A fração pesada engloba o $\mathrm{C}$ ligado aos minerais do solo e apresenta grau avançado de decomposição. $\mathrm{O}$ teor de $\mathrm{C}$ associado a essa fração contribui com a maior parte do $\mathrm{C}$ encontrado nos solos e engloba frações de maior estabilidade química associadas à argila, ao silte e à areia (Christensen, 1992). Em áreas onde é comum a remoção de resíduos e a baixa produção de biomassa, com freqüente revolvimento do solo, ocorrem reduções no estoque de matéria orgânica, em conseqüência da decomposição preferencial de frações mais lábeis de $\mathrm{C}$, em relação às de menor biodisponibilidade (Feller \& Beare, 1997; Freixo et al., 2002a, 2002b), e há, na fração argila, um enriquecimento relativo de compostos orgânicos processados pelos microrganismos (Tiessen \& Stewart, 1983).

Nos últimos anos, é freqüente o uso agrícola do lodo de esgoto como fonte de nutrientes às plantas e de matéria orgânica para o solo. Em solos tropicais, os efeitos da adição de lodo sobre o C orgânico podem ser temporários (Melo et al., 1994) ou duradouros (Marques, 1996; Oliveira et al., 2002), tendo sido verificado, em longo prazo, aumentos lineares nos teores de $\mathrm{C}$ orgânico, com a aplicação de doses crescentes de lodo (Dias et al., 2007). Esses aumentos dependem das taxas de decomposição do lodo no solo e dos fatores que a condicionam (Oliveira et al., 2002). De acordo com Fernandes et al. (2005), a aplicação de lodo de esgoto aumenta o fluxo de $\mathrm{CO}_{2}, \mathrm{~N}_{2} \mathrm{O}$ e $\mathrm{CH}_{4}$ para a atmosfera, contudo isso não implica em menor estoque de $\mathrm{C}$ orgânico no solo. Além de alterar o teor da $\mathrm{MO}$, o lodo pode exercer influência sobre sua composição química, pois os solos tratados com esse resíduo podem apresentar menor quantidade de $\mathrm{C}$ lábil (C-carboidrato) e maior presença de óleos e graxas, em relação aos solos não tratados (Hohla et al., 1978).

Com o emprego da técnica de fracionamento físico-densimétrico da $\mathrm{MO}$, é possível separar o $\mathrm{C}$ associado à $\mathrm{FL}$, do $\mathrm{C}$ associado à fase mineral ou fração pesada, já que são quantificadas frações que se distinguem uma das outras em relação à composição e localização física no solo, e que respondem diferentemente às práticas de manejo (Preston, 1996). Trabalhos realizados no Brasil apontam as frações descritas anteriormente como indicadores sensíveis às alterações na $\mathrm{MO}$, acarretadas pelas práticas de manejo do solo (Freixo et al., 2002a, 2002b; Roscoe \& Buurman, 2003; Pinheiro et al., 2004). Assim, a quantificação do $C$ em frações pode ser ferramenta importante na avaliação do efeito da aplicação de lodo de esgoto sobre a matéria orgânica do solo e seus compartimentos.

Este trabalho teve por objetivo avaliar a influência do uso continuado de doses crescentes de lodo de esgoto sobre os teores de $\mathrm{C}$ orgânico e de $\mathrm{C}$ nas frações leve e pesada da matéria orgânica de Latossolo.

\section{Material e Métodos}

As amostras de solo foram coletadas na camada 0-10 cm de profundidade, no Campo Experimental da Embrapa Meio Ambiente, em Jaguariúna, a $22^{\circ} 41^{\prime} \mathrm{S}, 47^{\circ} \mathrm{W}$ e à altitude de $570 \mathrm{~m}$, em área de Latossolo Vermelho distroférrico de textura argilosa (Embrapa, 2006). Trata-se de experimento multidisciplinar, instalado para avaliar, em longo prazo, os efeitos do lodo sobre diversos atributos do solo e da planta. As determinações analíticas foram realizadas no Laboratório de Estudo da Matéria Orgânica do Solo do Departamento de Ciência do Solo da Universidade Federal de Lavras, de agosto de 2003 a dezembro de 2004.

O lodo de esgoto utilizado no experimento foi fornecido pela Estação de Tratamento de Esgoto de Barueri, SP, que trata esgoto doméstico e industrial. Antes de cada aplicação no campo, foi coletada uma amostra representativa do lodo de esgoto utilizado, para determinação da composição química apresentada na Tabela 1. Também estão apresentadas as doses de lodo de esgoto e de adubo mineral, utilizadas para cada cultivo de milho realizado.

O experimento foi constituído por seis tratamentos, distribuídos em delineamento de blocos ao acaso, com três repetições, com parcelas experimentais 
de $10 \times 20 \mathrm{~m}$, perfazendo em área total de $200 \mathrm{~m}^{2}$ cultivada com milho. Em campo, foram implantadas parcelas com aplicação de doses crescentes de lodos oriundos de Barueri, SP, e Franca, SP. No presente estudo, foram avaliadas somente as parcelas adubadas com o lodo de Barueri. Os tratamentos avaliados foram: testemunha sem adição de lodo (L0); adubação mineral (AM), tratamento em que se realizou a adubação mineral com $70 \mathrm{~kg} \mathrm{ha}^{-1} \mathrm{de} \mathrm{N}$, de $\mathrm{P}_{2} \mathrm{O}_{5}$ e de $\mathrm{K}_{2} \mathrm{O}$, indicada para a cultura do milho (Raij et al., 1996); aplicação de lodo de esgoto para suprir a mesma quantidade de $\mathrm{N}$ fornecida na adubação mineral (L1) e duas (L2), quatro (L4) e oito (L8) vezes a dose de $\mathrm{N}$ aplicada em L1. Como referência, amostrou-se uma área sob mata nativa, adjacente ao local do experimento, que apresentava vegetação do tipo semi-caducifólia, similar à vegetação de mata do tipo cerradão; o Latossolo desse local foi similar, em termos de propriedades e características gerais, ao solo da área experimental.

As doses de lodo de esgoto, aplicadas em base seca, foram calculadas tendo-se como base os teores de $\mathrm{N}$ total e de $\mathrm{N}$ mineral, no caso do terceiro, quinto e sexto cultivos de milho, presentes no lodo. $\mathrm{O}$ índice de conversão de $\mathrm{N}$ orgânico para $\mathrm{N}$ mineral utilizado no cálculo foi de $30 \%$, tendo-se considerado, assim, uma taxa de mineralização de $30 \%$ do $\mathrm{N}$ orgânico presente no lodo, conforme as recomendações da Norma P 4230 (Cetesb, 1999). O requerimento de $\mathrm{N}$ pelo milho foi calculado considerando-se a classe de resposta média ao $\mathrm{N}$ aplicado com produtividade esperada na faixa de 6-8 $\mathrm{Mg} \mathrm{ha}^{-1}$ de grãos (Raij et al., 1996). Nos tratamentos em que o lodo de esgoto foi aplicado, foi feita, quando necessária, uma suplementação com $\mathrm{KCl}$, para fornecer a quantidade de K necessário ao milho no plantio.

O experimento foi implantado em 1999, na área experimental da Embrapa Meio Ambiente e, desde então, tem sido anualmente adubado com doses crescentes de lodo de esgoto oriundo da ETE Barueri. Até o presente trabalho, já foram realizados seis cultivos sucessivos com milho, com aplicações de doses acumuladas de lodo que corresponderam, em base seca, a: 0 (L0), 30 (L1), 60 (L2), 120 (L4) e $240 \mathrm{Mg} \mathrm{ha}^{-1}$ (L8). Após cada ciclo de cultivo de milho, os restos culturais foram retirados da área experimental, para não haver interferência na análise do efeito de doses de lodo de esgoto sobre os teores de matéria orgânica do solo.

O lodo de esgoto foi distribuído a lanço, em área total das parcelas experimentais, e incorporado ao solo à profundidade de $20 \mathrm{~cm}$, com o auxílio de enxada rotativa e arado de disco. Para as determinações laboratoriais, as amostras de solo foram coletadas 60 dias após a sexta aplicação de lodo, nas camadas de $0-10 \mathrm{~cm}$, secadas ao ar e, em seguida, moídas, passadas em peneira de $2 \mathrm{~mm}$ e caracterizadas quimicamente (Silva, 1999).

No cultivo de milho, foram utilizadas a variedade CATI AL30, que é milho safrinha conduzido sob irrigação (plantio em 5/4/1999); o híbrido AG1043 (plantio em 13/12/1999); o híbrido Savana 133S (plantio em 30/10/2000 e 5/11/2001); e a variedade Savana 1335 (plantio em 22/11/2002 e 18/12/2003).

Tabela 1. Características químicas dos lotes de lodo de esgoto utilizados no tratamento do solo, em seis ciclos de cultivo de milho, e quantidades de lodo de esgoto e de $\mathrm{N}, \mathrm{P}_{2} \mathrm{O}_{5}$ e $\mathrm{K}_{2} \mathrm{O}$ aplicadas via fertilizantes minerais.

\begin{tabular}{|c|c|c|c|c|c|c|c|}
\hline \multirow{2}{*}{$\begin{array}{l}\text { Característica e } \\
\text { tratamento }^{(1)}\end{array}$} & \multicolumn{6}{|c|}{ Cultivo $^{(2)}$} & \multirow[t]{2}{*}{ Total } \\
\hline & $1^{\mathrm{o}}$ & $2^{\underline{0}}$ & $3^{\mathrm{o}}$ & $4^{0}$ & $5^{0}$ & $6^{0}$ & \\
\hline $\mathrm{pH}_{\text {água }}{ }^{(3)}$ & 6,6 & 6,4 & 6,4 & 8,5 & 8,0 & 8,3 & - \\
\hline $\mathrm{C}\left(\mathrm{g} \mathrm{kg}^{-1}\right)^{(3)}$ & 248 & 271 & 293 & 354 & 534 & 312 & - \\
\hline $\mathrm{N}$ total $\left(\mathrm{g} \mathrm{kg}^{-1}\right)^{(4)}$ & 21 & 49,7 & 42,1 & 40,8 & 79,7 & 43,5 & - \\
\hline Umidade $\left(\mathrm{g} \mathrm{kg}^{-1}\right)^{(4)}$ & 664 & 802 & 712 & 795 & 788 & 812 & - \\
\hline $\mathrm{AM}\left(\mathrm{kg} \mathrm{ha}^{-1}\right)$ & $50+80+64$ & $90+90+72$ & $100+90+72$ & $90+70+56$ & $100+70+72$ & $70+70+50$ & - \\
\hline $\mathrm{L} 0\left(\mathrm{Mg} \mathrm{ha}^{-1}\right)$ & 0,0 & 0,0 & 0,0 & 0,0 & 0,0 & 0,0 & 0 \\
\hline L1 $\left(\mathrm{Mg} \mathrm{ha}^{-1}\right)$ & $8(3)$ & $4(28)$ & $5,6(40)$ & $5,6(87)$ & $3,2(57)$ & $3,8(36)$ & 30 \\
\hline L2 $\left(\mathrm{Mg} \mathrm{ha}^{-1}\right)$ & 16 & $8(19)$ & $10,9(8)$ & $10,9(69)$ & $6,5(45)$ & $7,7(21)$ & 60 \\
\hline $\mathrm{L} 4\left(\mathrm{Mg} \mathrm{ha}^{-1}\right)$ & 32 & $16(4)$ & 21,5 & $21,5(33)$ & $13(21)$ & 16 & 120 \\
\hline L8 $\left(\mathrm{Mg} \mathrm{ha}^{-1}\right)$ & 64 & 32 & 43 & 43 & 26 & 32 & 240 \\
\hline
\end{tabular}

${ }^{(1)} \mathrm{AM}$, fertilização mineral expressa em $\mathrm{N}+\mathrm{P}_{2} \mathrm{O}_{5}+\mathrm{K}_{2} \mathrm{O}$; L0, testemunha sem adição de lodo; aplicação de lodo de esgoto para suprir a mesma quantidade de $\mathrm{N}$ fornecida na adubação mineral (L1) e duas (L2), quatro (L4) e oito (L8) vezes a dose de N aplicada em L1. ${ }^{(2)}$ Valor entre parênteses indica a quantidade de $\mathrm{K}_{2} \mathrm{O}$, em kg ha ${ }^{-1}$, utilizada para complementar o $\mathrm{K}$ fornecido pelo lodo e atender a exigência nutricional do milho. ${ }^{(3)}$ Determinados no IAC (Campinas, SP), conforme protocolo analítico da EPA - SW-846-3051, descrito em EPA (1986) e valores expressos com base no material seco. ${ }^{(4)}$ Valores determinados em amostras recebidas nas condições originais, na Embrapa Meio Ambiente. 
O teor de C orgânico, em cada unidade experimental, foi determinado pelo método proposto por Yeomans \& Breemner (1988), cujo princípio é a oxidação do $\mathrm{C}$ orgânico a quente e úmido com dicromato de potássio, e titulação do dicromato remanescente com sulfato ferroso amoniacal. Para realizar a extração das frações leve (FL) e pesada, seguiram-se os procedimentos descritos em Machado (2002) e Sohi et al. (2001), com todas as análises realizadas em triplicata. Em frascos de centrífuga de $55 \mathrm{~mL}$, foram adicionados $5 \mathrm{~g}$ de TFSA e $35 \mathrm{~mL}$ de uma solução de iodeto de sódio (NaI) com densidade de $1,80 \mathrm{~g} \mathrm{~cm}^{-3}$. A mistura foi agitada manualmente por $30 \mathrm{~s}$ e centrifugada a $10.000 \mathrm{rpm}$ durante $15 \mathrm{~min}$. A FL sobrenadante foi aspirada e separada da solução de $\mathrm{NaI}$ por filtração a vácuo com uso de filtro de papel. A FL obtida, juntamente com os filtros de papel (secados a $65^{\circ} \mathrm{C}$ e pré-pesados), foi levada à estufa a $65^{\circ} \mathrm{C}$ por 72 horas; em seguida, foi separada do filtro de papel com uso de pincel, sem coleta de material do filtro, pesada, macerada em almofariz, peneirada (malha de 0,21 $\mathrm{mm}$ ) e armazenada em dessecador, para posterior determinação do teor de C. O solo restante no frasco de centrífuga, com a solução de $\mathrm{NaI}$, foi centrifugado por três vezes consecutivas com água destilada, para a remoção da solução de NaI residual. Nessa mesma amostra de solo, a fração pesada foi separada, para se quantificar o C associado às frações texturais do solo, conforme Gavinelli et al. (1995). Adicionaram-se ao material de solo remanescente $0,5 \mathrm{~g}$ de hexametafosfato (HMP) e $250 \mathrm{~mL}$ de água destilada, mistura essa que foi agitada por aproximadamente 14 horas. Em seguida, a areia foi separada de outras partículas por peneiramento úmido em malha de $53 \mu \mathrm{m}$; o silte $(2-53 \mu \mathrm{m})$ e a argila $(0-2 \mu \mathrm{m})$ foram separados a partir de alíquotas das frações granulométricas de 0-2 $\mu \mathrm{m}$ e $0-53 \mu \mathrm{m}$, coletadas com base no tempo de sedimentação dessas frações. As alíquotas obtidas foram acondicionadas em béquer e secadas a $65^{\circ} \mathrm{C}$; a seguir, essas frações foram pesadas, maceradas e moídas, para posterior determinação do teor de C. $\mathrm{O}$ teor de $\mathrm{C}$ nas frações leve e pesada da MO foi determinado de acordo com Yeomans \& Bremner (1988). Os teores de $\mathrm{C}$ na fração silte foram obtidos indiretamente, com base nos teores de $\mathrm{C}$ na argila e na fração silte + argila (Gavinelli et al., 1995).
A partir dos teores de C-FL e de $\mathrm{C}$ ligado às frações pesadas, foram determinados os percentuais de $\mathrm{C}$ em cada uma das frações estudadas, tendo-se como referência o teor total de $\mathrm{C}$ orgânico em cada unidade experimental.

Os dados obtidos foram submetidos à análise de variância e de regressão, tendo-se utilizado as três repetições de campo, pelo programa estatístico SISVAR (Ferreira, 2003).

\section{Resultados e Discussão}

A aplicação de lodo de esgoto promoveu aumento no teor de C orgânico, na camada de $0-10 \mathrm{~cm}$ do solo, que foi direta e linearmente proporcional à dose utilizada (Figura 1). No tratamento em que se adicionou ao solo dose acumulada de $240 \mathrm{Mg} \mathrm{ha}^{-1} \mathrm{de}$ lodo, correspondente a oito vezes a quantidade de $\mathrm{N}$ recomendada (L8) para o milho, houve aumento de $92,6 \%$ no teor de $\mathrm{C}$ orgânico em relação à testemunha. Aumentos dos teores de $\mathrm{C}$ orgânico em relação à testemunha também foram verificados na área que recebeu adubação mineral e na mata que, contudo, foram menores que os proporcionados pela aplicação de lodo. Os resultados obtidos concordam com aqueles apresentados por Dias et al. (2007), que estudaram - na mesma área e com as mesmas amostras do presente estudo - os efeitos da aplicação de dose continuada de lodo sobre os teores e estoques de $\mathrm{C}$ orgânico e de $\mathrm{C}$ ligado às substâncias húmicas no solo. O lodo é uma fonte importante de $\mathrm{C}$ e, além disso, melhora os atributos do solo, proporcionando melhor crescimento da parte aérea e raízes do milho,

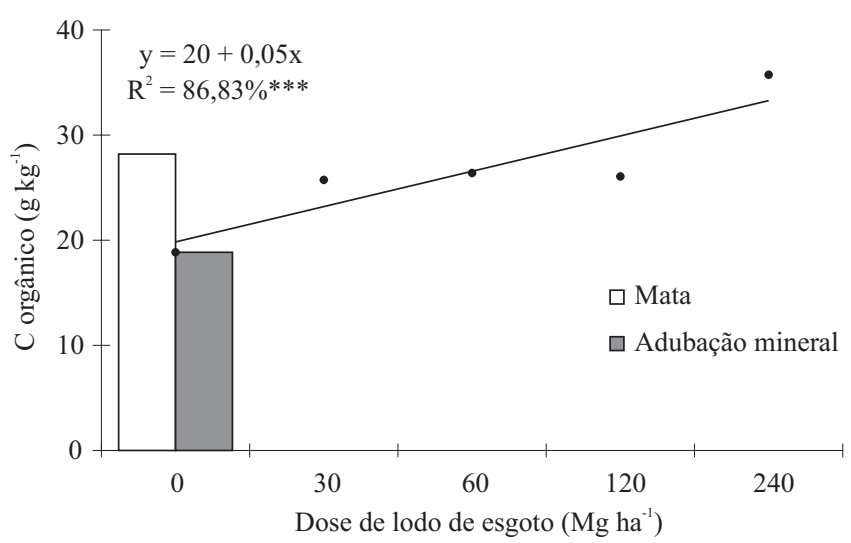

Figura 1. Efeito das doses de lodo de esgoto sobre o teor de carbono orgânico após seis aplicações sucessivas. ***Significativo a $0,1 \%$ de probabilidade. 
o que condiciona o maior aporte de $\mathrm{C}$, principalmente pelas raízes, tendo-se em vista que a parte aérea foi retirada das parcelas experimentais. Maior retenção de C orgânico foi verificada por Oliveira et al. (2002), em solo cultivado com cana-de-açúcar e tratado com lodo, em dois anos consecutivos, com a aplicação de doses crescentes de lodo que variaram de 70 a $211 \mathrm{Mg} \mathrm{ha}^{-1}$. Por conter maior quantidade de substâncias húmicas de natureza mais recalcitrante, é bastante provável que o $\mathrm{C}$ oriundo do lodo permaneça no solo por mais tempo, o que explica o acréscimo nos teores de $\mathrm{C}$ orgânico do solo.

Em relação ao fracionamento físico-densimétrico da $\mathrm{MO}$, observou-se que o único compartimento de $\mathrm{C}$ que respondeu às aplicações contínuas de lodo de esgoto foi a fração leve (FL) (Figura 2), em que se nota acréscimo no peso com o aumento da dose de lodo até $120 \mathrm{Mg} \mathrm{ha}^{-1}$.

O teor de FL no solo variou de 1,88 a $6,9 \mathrm{~g} \mathrm{~kg}^{-1}$. Roscoe \& Buurman (2003) verificaram, em um Latossolo sob plantio convencional cultivado com milho, o teor de $7 \mathrm{~g} \mathrm{~kg}^{-1}$ de FL. Janzen et al. (1992) observaram valores superiores, na faixa de 6,1 a $14 \mathrm{~g} \mathrm{~kg}^{-1}$, sob condições de clima temperado, o que se explica pelo fato de, sob condições tropicais, ocorrer uma reciclagem mais rápida dessa fração, o que compromete o seu acúmulo em solo. A FL apresenta tempo de meia-vida reduzido no solo e pode sofrer alterações em razão de fatores que governam a decomposição da matéria orgânica, como a temperatura e a umidade do solo, além de ser afetada também por aspectos ligados à quantidade e à composição química do resíduo aplicado.

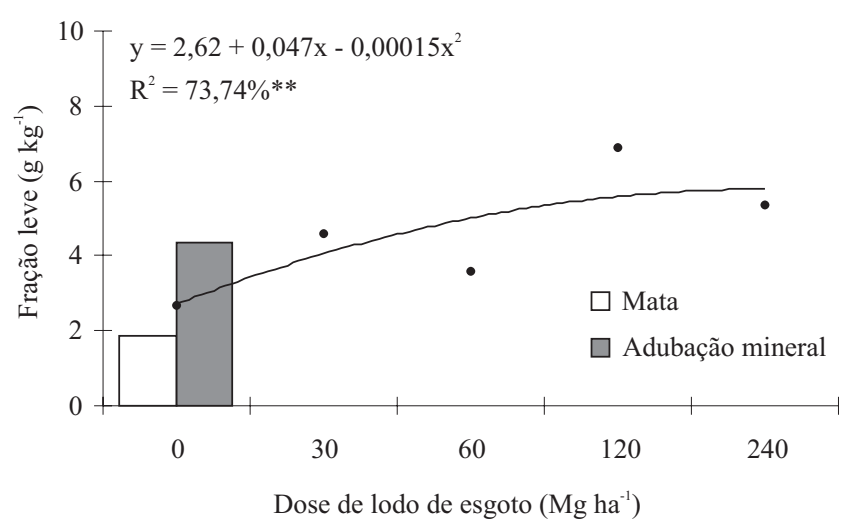

Figura 2. Efeito das doses de lodo de esgoto sobre o teor de fração leve, após seis aplicações sucessivas. **Significativo a $1 \%$ de probabilidade.
Os teores do $\mathrm{C}$ associado à $\mathrm{FL}$ (C-FL) variaram de 0,57 a $2,17 \mathrm{~g} \mathrm{~kg}^{-1}$ (Figura 3) e estão dentro da faixa verificada em outros trabalhos (Leite, 2001; Freixo et al., 2002a, 2002b; Pinheiro et al., 2004). Na Figura 3 A, podem ser observados acréscimos no $\mathrm{C}-\mathrm{FL}$, em relação à testemunha, proporcionados pelas crescentes doses de lodo de esgoto, de: 89,5, $53,6,179,4$ e $110,7 \%$, para as doses de $30,60,120$ e $240 \mathrm{Mgha}^{-1}$, respectivamente. Os aumentos nos teores de C-FL são inversos aos valores de $\mathrm{C}$ da biomassa microbiana (C-BM), obtidos por Soares (2005), em estudo realizado na mesma área experimental. No estudo de Soares (2005) os aumentos de C-BM em relação à testemunha foram de $17,24 \%$ na dose $30 \mathrm{Mg} \mathrm{ha}^{-1}, 79,3 \%$, na dose $60 \mathrm{Mg} \mathrm{ha}^{-1}, 19 \%$, na dose $120 \mathrm{Mg} \mathrm{ha}^{-1}$ e $29,3 \%$, na dose $240 \mathrm{Mg} \mathrm{ha}^{-1}$. Há, então, a possibilidade de imobilização temporária do $\mathrm{C}$ na $\mathrm{BM}$, em detrimento da FL, o que indica a ciclagem mais rápida dessa fração.

No estudo de Leite (2001), em área sob plantio direto, constatou-se menor teor de C-BM e maior teor de C-FL, em relação aos teores de $\mathrm{C}$ nesses compartimentos de $\mathrm{MO}$, em área de solo revolvido. Segundo esse autor, isso ocorreu em razão de o C-FL ser uma das principais fontes de substrato microbiano, o que explicaria a diminuição do $\mathrm{C}$ mais lábil (C-FL) no sistema plantio direto, em conseqüência do aumento do C-BM. Fließbach \& Mäder (2000) consideraram o fato de a FL servir como indicador e a BM como regulador da decomposição da MO no solo e Flie $\beta$ bach \& Mäder (2000), avaliaram a proporção de C-BM/ $\mathrm{C}$-FL como potencial indicador da qualidade do material orgânico adicionado para formar e manter a BM; além disso, ressaltaram a possibilidade de uma maior $\mathrm{BM}$ induzir decomposição mais rápida da MO e, conseqüentemente, afetar os teores da FL. O impacto da aplicação de lodo de esgoto no C-FL deve-se ao fato de que o único mecanismo de proteção que atua nesse compartimento é a recalcitrância química (Roscoe \& Machado, 2002), ou seja, a própria composição do material que, pela falta de proteção física (oclusão ou complexação), torna o material mais acessível ao ataque de microrganismos. No tratamento com uso de adubo mineral, houve aumento de $68,5 \%$ no C-FL em relação à testemunha. A aplicação de fertilizantes aumentou o teor de C-FL, provavelmente pelo fato 
de aumentar a produtividade em razão de o $\mathrm{N}$ ser prontamente disponível às plantas (Janzen et al., 1992). Em média, na área sob mata, o teor de C-FL foi $26 \%$ menor, em relação aos teores de C-FL observados nos tratamentos com adição de lodo de esgoto.

Os teores de C na fração pesada variaram de 1,21 a 2,49 $\mathrm{g} \mathrm{kg}^{-1}$ na areia; de 6,16 a $14,77 \mathrm{~g} \mathrm{~kg}^{-1}$ no silte; e de 9,75 a $16,8 \mathrm{~g} \mathrm{~kg}^{-1}$ na argila, resultados que estão dentro da faixa de teores para $\mathrm{C}$ ligado às frações pesadas verificada no estudo de Freixo et al. (2002a, 2002b), que avaliaram a dinâmica do C dessas mesmas frações, em Latossolos submetidos a diferentes combinações de preparo do solo, com esquemas de rotação de culturas. A adição de lodo promoveu aumento linear no C-areia (Figura 3 B) e no C-silte (Figura 3 C). Verifica-se que, com a diminuição do tamanho da partícula, ocorre aumento na capacidade do solo em armazenar C. Isso se explica, de acordo com Christensen (1992), pela redução observada na relação $\mathrm{C} / \mathrm{N}$ das frações granulométricas, que diminui com a redução do tamanho da partícula e indica um grau de humificação mais avançado no $\mathrm{C}$ associado às partículas mais finas (areia $<$ silte $<$ argila) do solo.

Pelo fato de não ter sido separada a fração leve intra-agregado (FLI), pode-se inferir que parte do C-areia seja oriundo desse compartimento de MO. Considerando-se essa hipótese, parte do $\mathrm{C}$ quantificado como $\mathrm{C}$-areia estaria parcialmente protegido do ataque de microrganismos dentro dos agregados, o que poderia ser uma das explicações para o acréscimo linear do $\mathrm{C}$-areia, à medida que aumentam as doses de lodo de esgoto. Além

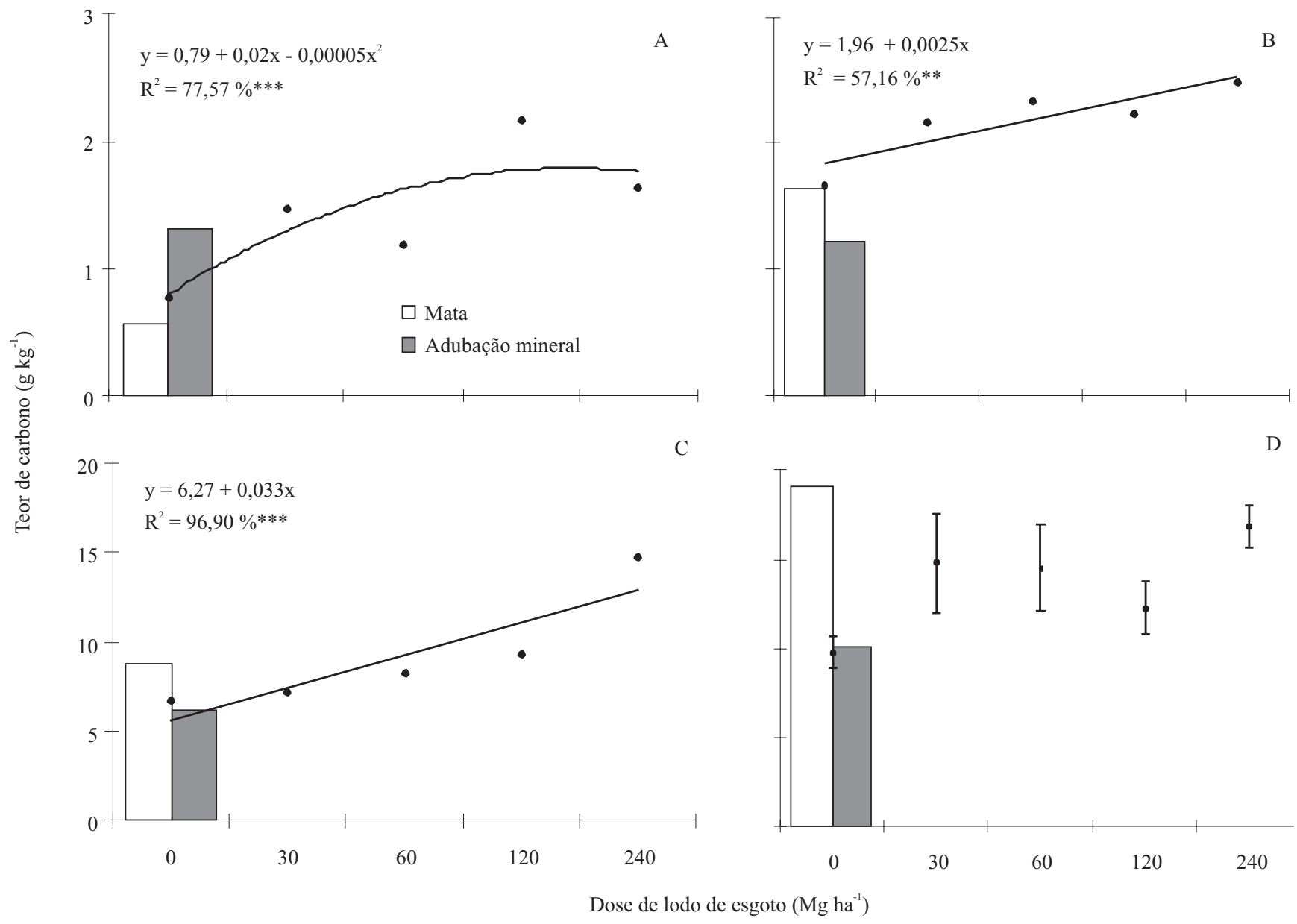

Figura 3. Efeito das doses de lodo de esgoto no teor de carbono ligado a fração leve (A), areia (B), silte (C) e argila (D), após seis aplicações sucessivas. $* *$ e ${ }^{* * *}$ Significativo a 1 e $0,1 \%$ de probabilidade, respectivamente. As barras verticais referem-se ao desvio-padrão da média. 
disso, os compostos orgânicos associados à areia apresentam outros mecanismos de proteção, além de maior grau de recalcitrância que o C-FL (Roscoe $\&$ Machado, 2002), o que pode explicar os aumentos de até $50,4 \%$ no $\mathrm{C}$-areia do tratamento com maior uso de lodo (240 $\left.\mathrm{Mg} \mathrm{ha}^{-1}\right)$, em relação à testemunha. Os aumentos observados para o C-silte, em conseqüência do uso de lodo, foram de até 119,4\%, quando se utilizou a maior dose de lodo, em relação à testemunha. Essa maior capacidade de acumular C orgânico, à medida que as doses aplicadas de lodo aumentam, deve-se à recalcitrância dessa fração granulométrica em relação ao C-areia. Assim, é provável que o $\mathrm{C}$-silte, por ser mais recalcitrante que o C-areia, tenha se acumulado mais no solo, à medida que o aporte do material orgânico aumentou, com menor grau de influência da microbiota. $\mathrm{O}$ teor de C-argila, não sofreu influência significativa da aplicação continuada de lodo esgoto. O C-argila, é uma das frações mais estabilizadas da $\mathrm{MO}$, tanto por ser constituída de material mais recalcitrante, como pela maior estabilidade química e física, conferida ao C orgânico quando em associação com a fase mineral do solo (Christensen, 1992, 1996). Portanto, é provável que seja necessário maior tempo para que se manifestem alterações no teor de C-argila, em razão do manejo diferenciado do solo e do uso de lodo de esgoto.

Em geral, o quadro constituído por todas as frações extraídas indica que a aplicação continuada de lodo de esgoto aumenta os teores de $\mathrm{C}$ nas frações leve e pesada, em relação à testemunha. O uso sistemático de lodo exerce, ainda, influência diferenciada sobre o C ligado às frações granulométricas, sendo notada, em alguns tratamentos, a tendência de decréscimo no C-FL, em detrimento de um enriquecimento de C nas frações pesadas, com a elevação das doses de lodo de esgoto. Uma ressalva que deve ser feita é a de que, ao invés de se discutirem os teores de $\mathrm{C}$ em cada fração da MO, seria razoável que se discutissem os estoques de $\mathrm{C}$ dessas mesmas frações, tendose em vista que a adição de lodo de esgoto pode alterar os valores de densidade do solo. Entretanto, conforme pode ser verificado no estudo de Dias et al. (2007), a densidade do solo não foi afetada pela adição de doses crescentes de lodo, tendo sido notadas pequenas variações não-significativas desse atributo entre as doses de lodo de esgoto testadas, o que justifica a apresentação e discussão dos dados em relação aos teores de $\mathrm{C}$ em cada fração. A recuperação do teor total do $\mathrm{C}$ orgânico nas amostras obtidas, via fracionamento físicodensimétrico, foi satisfatória no presente estudo, com média de 107 \% de recuperação do C orgânico, entre os tratamentos avaliados (Tabela 2).

Entre as proporções de $\mathrm{C}$ ligado às frações granulométricas e C-FL com o C orgânico, somente se observou efeito significativo da doses de lodo sobre a relação C-FL/C orgânico (Figura 4). O C-FL representou uma pequena parte do C orgânico. Em solos tropicais, em condições de cultivo, esses valores têm sido menores do que os observados em áreas de regiões temperadas. Os valores dessas proporções, no presente estudo, variaram de 3,03 a 7,81\%. Em geral, foram observados acréscimos na relação C-FL/C orgânico de até $70,66 \%$, no L4, tendo-se constatado diminuiçãodessa relação no L8. Os percentuais de C-areia (Figura 4 B), C-silte (Figura 4 C) e C-argila (Figura 4 D), em todos os tratamentos avaliados, em relação ao C orgânico, estiveram dentro das faixas $5,9-9,8 \%, 30,8-45,2 \%$ e 44,5-85,2\%, respectivamente, e não foi verificado efeito das doses de lodo sobre essas relações. A maior proporção do $\mathrm{C}$ orgânico encontra-se associado à fração pesada, notadamente à fração argila.

Tabela 2. Recuperação do carbono das frações da matéria orgânica de um Latossolo submetido a doses crescentes de lodo de esgoto e cultivado com milho.

\begin{tabular}{|c|c|c|c|c|c|c|}
\hline \multirow[t]{2}{*}{ Tratamento $^{(1)}$} & \multicolumn{4}{|c|}{ Frações da matéria orgânica } & \multirow[t]{2}{*}{$\Sigma \mathrm{C}$ frações } & \multirow[t]{2}{*}{ Recuperação ${ }^{(2)}$} \\
\hline & C-argila & C-silte & $\mathrm{C}$-areia & $\mathrm{C}-\mathrm{FL}^{(3)}$ & & \\
\hline & \multicolumn{5}{|c|}{ 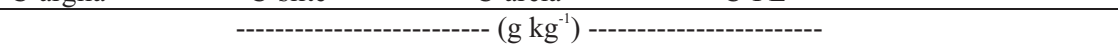 } & ------ (\%) ------ \\
\hline $\mathrm{AM}$ & 10,10 & 6,16 & 1,22 & 1,31 & 18,79 & 92,1 \\
\hline $0\left(\mathrm{Mg} \mathrm{ha}^{-1}\right)$ & 9,75 & 6,73 & 1,66 & 0,78 & 18,92 & 111,4 \\
\hline $30\left(\mathrm{Mg} \mathrm{ha}^{-1}\right)$ & 14,79 & 7,28 & 2,18 & 1,47 & 25,72 & 109,0 \\
\hline $60\left(\mathrm{Mg} \mathrm{ha}^{-1}\right)$ & 14,50 & 8,28 & 2,35 & 1,19 & 26,32 & 105,6 \\
\hline $120\left(\mathrm{Mg} \mathrm{ha}^{-1}\right)$ & 12,27 & 9,36 & 2,25 & 2,17 & 26,05 & 94,6 \\
\hline $240\left(\mathrm{Mg} \mathrm{ha}^{-1}\right)$ & 16,83 & 14,77 & 2,50 & 1,64 & 35,74 & 109,3 \\
\hline Mata & 16,52 & 8,79 & 1,93 & 0,93 & 28,17 & 127,8 \\
\hline
\end{tabular}

${ }^{(1)}$ AM: adubação mineral com formulado NPK. ${ }^{(2)} 100$ (somatório do C em frações da MO/C orgânico). ${ }^{(3)}$ FL: fração leve. 


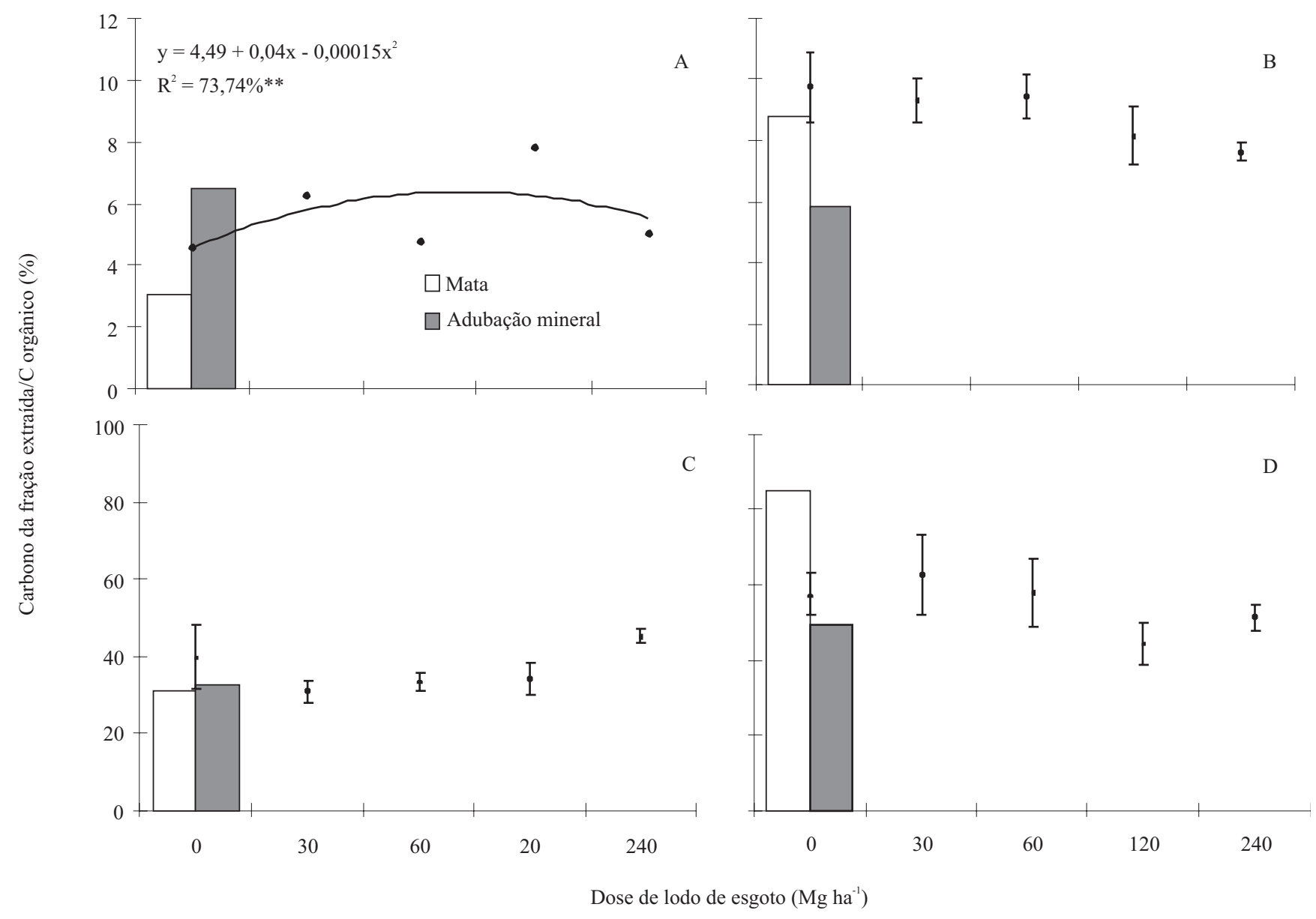

Figura 4. Efeito das doses de lodo de esgoto, na relação C da fração leve/C orgânico (A), C da areia/C orgânico (B), C do silte/C orgânico (C) e C da argila/C orgânico (D), após seis aplicações sucessivas. **Significativo a 1\% de probabilidade. As barras verticais referem-se ao desvio-padrão da média.

A área sob mata apresentou maior relação de C-argila/C orgânico o que, possivelmente, se explica pela estabilização química e física do $\mathrm{C}$ associado à argila, mecanismo esse que confere maior proteção à MO. Em razão da amplitude de variação, os resultados obtidos mostram que C-FL é um indicador mais sensível das alterações de manejo sobre os "pools" de $\mathrm{MO}$, em relação ao $\mathrm{C}$ ligado às frações pesadas, o que está de acordo com os dados obtidos por Freixo et al. (2002b).

\section{Conclusões}

1. Há aumento acentuado dos teores de C orgânico pela aplicação de lodo de esgoto, uma vez que a aplicação da maior dose $\left(240 \mathrm{Mg} \mathrm{ha}^{-1}\right)$ praticamente dobrou o $\mathrm{C}$ armazenado no solo, em relação à área sem utilização do resíduo; as áreas cultivadas com aplicação de lodo de esgoto possuem maiores teores de $\mathrm{C}$ orgânico do que a área sob mata e do que aquela com uso exclusivo de adubo mineral.

2. Os maiores teores de $\mathrm{C}$ no solo estão associados à fração argila, independentemente da dose de lodo de esgoto aplicada.

3. Os teores de C orgânico associado ao compartimentos da matéria orgânica do solo têm a seguinte ordem de contribuição: $\mathrm{C}$-fração leve $<\mathrm{C}$-areia $<\mathrm{C}$-silte $<\mathrm{C}$-argila; há acréscimo linear nos teores de $\mathrm{C}$ orgânico associado à areia e ao silte, com a adição de doses crescentes de lodo de esgoto ao solo.

4. A aplicação de doses acumuladas de até $120 \mathrm{Mg} \mathrm{ha}^{-1}$ de lodo de esgoto aumenta a biodisponibilidade da matéria orgânica do solo, pela maior presença da fração leve no solo e de C associado a esta fração. 


\section{Agradecimentos}

Ao Conselho Nacional de Desenvolvimento Científico e Tecnológico, pelo financiamento; ao Dr. Manoel Dornelas de Souza, Embrapa Meio Ambiente, pelas valiosas sugestões e ajuda na revisão; à equipe da Embrapa Meio Ambiente, responsável pela manutenção e condução do estudo que trata da "Avaliação do impacto ambiental do uso agrícola de lodo de esgoto".

\section{Referências}

CETESB. Aplicação de lodos de sistemas de tratamento biológico em áreas agrícolas: critérios para projeto e operação. São Paulo, 1999. 32p. (Norma P 4230).

CHRISTENSEN, B.T. Carbon in primary and secondary organomineral complexes. In: CARTER, M.R.; STEWART, B.A. (Ed.). Structure and organic matter storage in agricultural soil. Boca Raton: CRC Press, 1996. p.97-165.

CHRISTENSEN, B.T. Physical fractionation of soil and organic matter in primary particle size and density separates. Advances in Soil Science, v.20, p.1-90, 1992.

DIAS, B. de O.; SILVA, C.A.; SOARES, E.M.B.; BETTIOL, W. Estoque de carbono e quantificação de substâncias húmicas em Latossolo submetido à aplicação contínua de lodo de esgoto. Revista Brasileira de Ciência do Solo, v.31, p.701-711, 2007.

EMBRAPA. Sistema brasileiro de classificação de solos. Rio de Janeiro: Embrapa Solos, 2006. 306p.

EPA. Test methods for evaluating solid waste: physical/chemical methods. $3^{\text {rd }}$ ed. Washington: Government Printing Office, 1986. (SW-846-3051).

FELLER, C.; BEARE, M.H. Physical control of soil organic matter dynamics in the tropics. Geoderma, v.79, p.69-116, 1997.

FERNANDES, S.A.P.; BETTIOL, W.; CERRI, C.C.; CAMARGO, P. Sewage sludge effects on gas fluxes at the soil-atmosphere interface, on soil $\delta^{13} \mathrm{C}$ and on total soil carbon and nitrogen. Geoderma, v.125, p.49-57, 2005.

FERREIRA, D.F. SISVAR: software: versão 4.6. Lavras: DEX/ UFLA, 2003. Software.

FLIE $\beta$ BACH, A.; MÄDER, P. Microbial biomass and size-density fractions differ between soils of organic and conventional agricultural systems. Soil Biology and Biochemistry, v.32, p.757-768, 2000.

FREIXO, A.A.; MACHADO, P.L.O. de A.; GUIMARÃES, C.M.; SILVA, C.A.; FADIGAS, F. de S. Estoques de carbono e nitrogênio e distribuição de frações orgânicas de Latossolo do Cerrado sob diferentes sistemas de cultivo. Revista Brasileira de Ciência do Solo, v.26, p.425-434, 2002a.

FREIXO, A.A.; MACHADO, P.L.O. de A.; SANTOS, H.P. dos; SILVA, C.A.; FADIGAS, F. de S. Soil organic carbon and fractions of a Rhodic Ferralsol under the influence of tillage and crop rotation systems in Southern Brazil. Soil and Tillage Research, v.64, p.221-230, 2002b.

GAVINELLI, E.; FELLER, C.; LARRÉ-LARROUY, M.C.; BACYE, B.; DJEGUI, N. A routine method to study soil organic matter by particle-size fractionation: examples for tropical soils. Communications in Soil Science and Plant Analysis, v.26, p.1749-1760, 1995.

HOHLA, G.N.; JONES, R.L.; HINESLY, T.D. The effect of anaerobically digested sewage sludge on organic fractions of blount silt loam. Journal of Environment Quality, v.7, p.559-563, 1978.

JANZEN, H.H.; CAMPBELL, C.A.; BRANDT, S.A.; LAFOND, G.P.; TOWNLEY-SMITH, L. Light-fraction organic matter in soils from long-term crop rotations. Soil Science Society of America Journal, v.56, p.1799-1806, 1992.

LEITE, L.F.C. Compartimentos e dinâmica da matéria orgânica do solo sob diferentes manejos e sua simulação pelo modelo Century. 2001. 146p. Tese (Doutorado) - Universidade Federal de Viçosa, Viçosa.

MACHADO, P.L.O. de A. Fracionamento físico do solo por densidade e granulometria para a quantificação de compartimentos da matéria orgânica do solo: um procedimento para a estimativa pormenorizada do seqüestro de carbono pelo solo. Rio de Janeiro: Embrapa Solos, 2002. 6p. (Embrapa Solos. Comunicado Técnico, 9).

MARQUES, M.O. Incorporação de lodo de esgoto em solo cultivado com cana-de-açúcar. 1996. 111p. Tese (Livre Docência) - Universidade Estadual Paulista, Jaboticabal.

MELO, W.J.; MARQUES, M.O.; SANTIAGO, G.; CHELLI, R.A.; LEITE, S.A.S. Efeito de doses crescentes de lodo de esgoto sobre frações da matéria orgânica e CTC de um Latossolo cultivado com cana-de-açúcar. Revista Brasileira de Ciência do Solo, v.18, p.449-455, 1994.

OLIVEIRA, F.C.; MATTIAZZO, M.E.; MARCIANO, C.R.; ROSSETO, R. Efeitos de aplicações sucessivas de lodo de esgoto em um Latossolo Amarelo distrófico cultivado com cana-de-açúcar: carbono orgânico, condutividade elétrica, $\mathrm{pH}$ e CTC. Revista Brasileira de Ciência do Solo, v.26, p.505-519, 2002.

PINHEIRO, E.F.M.; PEREIRA, M.G.; ANJOS, L.H.C.; MACHADO, P.L.O. de A. Fracionamento densimétrico da matéria orgânica do solo sob diferentes sistemas de manejo e cobertura vegetal em Paty do Alferes (RJ). Revista Brasileira de Ciência do Solo, v.28, p.731-737, 2004.

PRESTON, C.M. Applications of NMR to soil organic matter analysis: history and prospects. Soil Science, v.161, p.144-166, 1996.

RAIJ, B. van; CANTARELLA, H.; QUAGGIO, J.A.; FURLANI, A.M.C. Recomendações de adubação e calagem para o Estado de São Paulo. 2.ed. Campinas: IAC, 1996. 285p.

ROSCOE, R.; BUURMAN, P. Tillage effects on soil organic matter in density fractions of a Cerrado Oxisol. Soil and Tillage Research, v.70, p.107-119, 2003.

ROSCOE, R.; MACHADO, P.L.O. de A. Fracionamento físico do solo em estudos da matéria orgânica. Dourados: Embrapa Agropecuária Oeste; Rio de Janeiro: Embrapa Solos, 2002. 86p. 
SILVA, F.C. (Org.). Manual de análises químicas de solos, plantas e fertilizantes. Brasília: Embrapa Comunicação para Transferência de Tecnologia; Rio de Janeiro: Embrapa Solos; Campinas: Embrapa Informática Agropecuária, 1999. 370p.

SILVA, J.E.; RESCK, D.V.S. Matéria orgânica do solo. In: VARGAS, M.T.; HUNGRIA, M. (Ed.). Biologia dos solos dos Cerrados. Planaltina: Embrapa-CPAC, 1997. p.465-524.

SOARES, E.M.B. Impacto de aplicações sucessivas de lodo de esgoto sobre os compartimentos de carbono orgânico em Latossolo cultivado com milho. 2005. 82p. Dissertação (Mestrado) - Universidade Federal de Lavras, Lavras.

SOHI, S.; MAHIEU, N.; ARAH, J.R.M.; POWLSON, D.S.P.; MADARI, B.; GAUNT, J.L. A procedure for isolating soil organic matter fractions suitable for modeling. Soil Science Society of America Journal, v.65, p.1121-1128, 2001.

STEVENSON, F.J. Humus chemistry: genesis, composition, reactions. 2.ed. New York: John Wiley \& Sons, 1994. 496p.

TIESSEN, H.; STEWRT, J.W.B. Particle-size fractions and their use in studies of soil organic matter. II - Cultivation effects on organic matter composition in size fractions. Soil Science Society of America Journal, v.47, p.509-514, 1983.

YEOMANS, J.C.; BREMNER, J.M. A rapid and precise method for routine determination of organic carbon in soil.

Communications in Soil Science and Plant Analysis, v.19, p.1467-1476, 1988.

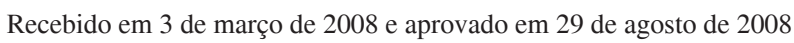

